\title{
Encountering Covid-19 and perceived stress and the role of a health climate among medical workers
}

\author{
Sammar Abbas $^{1}$ (D) $\cdot$ Hadi AL-Abrrow ${ }^{2}$ (D) Hasan Oudah Abdullah ${ }^{3}$ (D) $\cdot$ Alhamzah Alnoor $^{4}$ (D) Zeeshan Zaib Khattak $^{1} \cdot$ \\ Khai Wah Khaw ${ }^{5}$
}

Accepted: 14 January 2021 / Published online: 23 January 2021

(C) The Author(s), under exclusive licence to Springer Science+Business Media, LLC part of Springer Nature 2021

\begin{abstract}
Due to the outbreak of Covid-19 epidemic, work stress among health sector employees has risen too high. The study aims at determining the effect of the current coronavirus epidemic in the form of stress perceived among the medical workers in Pakistan and to discover the moderating role played by a healthy climate in offsetting it. The data was collected from 255 medical workers through a self-administered online questionnaire. Multiple Hierarchical Regression was used as a tool to test the hypotheses of the study. The results obtained indicate a correlation between the pandemic and the stress caused by it among the health workers, whereas, the role of a wholesome climate in the reduction of stress among them was found lacking. Sub-hypotheses indicate that the healthy environment provided by supervisors is effective in reducing the impact of workers' handling of the Covid-19 epidemic and perceived stress, while the healthy environment provided by hospitals in general or by workgroups fails to cause such positive change. This revelation necessitates the adoption of compulsory precautionary measures on the part of relevant authorities, because increase in stress caused by the pandemic can prove more lethal than the pandemic itself. The threat of the coronavirus pandemic has emerged as a massive socio-economic challenge for the global community, especially for the developing countries like Pakistan which faces serious socio-economic challenges in the current scenario. On account of the similarity of situations, the results obtained through this study can be safely generalized to other developing countries, particularly from the South Asian region.
\end{abstract}

Keywords Covid-19 $\cdot$ Perceived stress $\cdot$ Health climate $\cdot$ Medical workers

\section{Introduction}

Presently, the entire World bears a common agenda for countering the Covid-19. Resources of the world are being channelized to win the war against Covid-19, but so far, no worthwhile success has been achieved in this regard. When the first

Sammar Abbas

sabbas@kust.edu.pk

Hadi AL-Abrrow

hauni_2000@yahoo.com

Hasan Oudah Abdullah

hasan_oudah@yahoo.com

Alhamzah Alnoor

Alhamzah.alnoor@student.usm.my; alhamzah.malik@stu.edu.iq

Zeeshan Zaib Khattak

dr.zeeshan@kust.edu.pk

Khai Wah Khaw

khaiwah@usm.my wave of the pandemic surfaced in December 2019 at Wuhan in China. The Chinese Government responded quickly in containing the pandemic by locking down the city of Wuhan along with some other precautionary measures. However, due to mass migration, it failed in stopping its spread to other parts of the World (Qiu, Chen, \& Shi, 2020). The pandemic

1 Institute of Business Studies, Kohat University of Science and Technology, Kohat, Pakistan

2 Department of Business Administration, College of Administration and Economic, University of Basrah, Basrah, Iraq

3 Department of Business Administration, Basrah University College for Science and Technology, Basrah, Iraq

4 Southern Technical University, Management Technical College, Universiti Sains Malaysia, School of Management, George Town, Penang, Malaysia

5 School of Management, Universiti Sains Malaysia, 11800 George Town, Pulau Pinang, Malaysia 
has seriously affected the World's economies in many ways, like closure of businesses, rise in unemployment, decrease in exports, reduction in oil prices, increase in poverty, rise in death toll of the world population etc. World Health Organization (WHO) has warned countries of severe consequences, if they showed negligence in future. The pandemic has exposed the World to an unseen danger which may continue to exist for an indefinite period. Since the time the WHO declared coronavirus epidemic as a major threat to the health of the entire human community, it has caused distress internationally (Sohrabi et al., 2020).

Scientists from all parts of the world are consistently trying to discover a vaccine for curing the disease caused by coronavirus, however, so far, no considerable success has been achieved in rooting this malady out. Because of the heightened concerns and fears, Covid-19 is causing various psychological issues in the form of mental stress, anxiety, and psychological disorder. Though Covid-19 is causing mental stress among the masses, it causes more significant perceived stress among medical workers (Chen et al., 2020). Perceived stress refers to the feelings or thoughts that individuals have about how much they are stressed at a given point of time (Cohen, Kamarck, \& Mermelstein, 1994). Perceived stress has negative impact upon medical staff in terms of job performance and job satisfaction (Kumar \& Bhalla, 2019). Medical workers, including doctors, nurses, and paramedics are on the frontline in the fight against the pandemic. Though there have been many efforts to physically protect the medical workers by providing personal protective equipment (PPE) and other physical facilities, however, there is a dearth of research efforts undertaken to study the perceived stress being experienced by the medical workers (Shanafelt, Ripp, \& Trockel, 2020).

Covid-19 has, also exposed the world's health systems badly, especially in the developing and underdeveloped countries (Legido-Quigley et al., 2020). Due to non-readiness on the part of health system, we can witness a weakened health climate as far as Covid-19 is concerned (Shadmi et al., 2020). Health climate is a broader term and refers to the overall medical facilities and other medical equipment available in hospitals. It also includes psychological interventions (training of medical workers, mental health system, recognition, and support), government policies, financial support and supervisory relations (Ancarani, Di Mauro, \& Giammanco, 2017). Hospitals do not have sufficient capabilities to treat all patients; there is inadequate availability of PPE, insufficient prior knowledge about corona, absence of psychological interventions and alternate support program. Studies have found that a healthy and adequate health climate can mitigate the stress caused by Coivd-19 among medical workers (Hamouche, 2020).

South Asian developing countries like India, Pakistan, Sri Lanka and Bangladesh reported to be suffering from Covid-19 at the end of February 2020. Pakistan, officially, announced the outbreak of pandemic on Feb, 26, 2020, and till this point of time, out of the total 32,674 reported cases, the death toll is 724 and the cases of recovery are 8555 in number (Express News-Urdu, 2020). The figures mentioned above belong to a stage when the government has already launched and successfully completed an emergency financial support project by the name 'Eahsas Program', under which cash was distributed among the affectless and the needy people. The government has also offered financial packages to various sectors, including the health sector. Among all other sectors, the health sector, in particular, has adversely been affected and challenged by the Covid-19 outbreak. It has been witnessed that with the emergence of pandemic in Pakistan, the medical workers have faced multitude of problems in the form of high risk of exposure to the infection, physical and psychological panic, lack of personal protective arrangements, over-exhaustion and workfamily conflict (Urooj, Ansari, Siraj, Khan, \& Tariq, 2020). With every passing day, the severity of the virus is increasing as more and more positive cases, and deaths are being reported. This is intensifying the problem for medical workers and may leave long-lasting detrimental effects over their psychological well-being. Medical workers are more significantly experiencing the stress due to the absence of a supportive and well-equipped health climate (Rana, Mukhtar, \& Mukhtar, 2020).

The above discussion indicates that Covid-19 is not only a risk for the physical health of the masses but is also a serious threat to their psychological well-being. It also indicates that the medical workers are at a higher risk, as they are fighting on the front-line against the disease. Medical workers experience mental issues due to their direct contact with the patients. While all attention is being focused over the patients and over the preventive measures, concerns relating to the psychological wellbeing and mental health of the medical workers are being overlooked (Usman, Mamun, \& Ullah, 2020). Hence, there is a need to look into the issue from the perspective of effective human resource management. In this context, the current study aims at discovering the effect of the Pakistani health sector's workers handling of the COVID-19 epidemic on their perceived stress and to discover the moderating role played by a healthy climate provided by workgroups, supervisors, and hospitals. It is expected that the outcomes of this study will help to understand the nature and dimensions of the above-mentioned research problem in a novel context. It is also believed that the results of this study will help to develop and implement policy measures to combat Covid-19 effectively.

The perceived stress during a Covid-19 epidemic in Pakistan is discussed with mental health and emotional (Nanjundaswamy, Pathak, \& Chaturvedi, 2020), psychological impact (Qureshi et al., 2020), level of knowledge, attitude, practice (Jawed, Manazir, Zehra, \& Riaz, 2020), employees' 
commitment (Zandi, Shahzad, Farrukh, \& Kot, 2020), and psychological distress (Abid et al., 2020). We believe that most studies were limited to detection or diagnosis. Few of them paid attention to the importance of searching for tools to relieve stress during the epidemic. The current study attempts to do this by using hospitals' health climate as a moderator variable that may have a positive role in mitigation. This matter stimulates research on the impact of dealing with the Covid-19 epidemic in the Pakistani health sector and its effect on perceived stress while exploring the role of the health climate available on the ground in hospitals in general as a support for health workers.

To achieve this purpose, we will try in the next parts of the paper to discuss concepts and hypotheses development, then define the study's methodology. After that, we will extract the results obtained from testing the sample responses to the variables. Finally, we will discuss the results obtained and suggest the products' theoretical and practical implications and then suggest future research directions related to the paper's topic.

\section{Concepts and Hypotheses Development}

\section{The Outbreak of Covid-19}

Towards the end of December 2019, in Wuhan, China, patients with lungs inflammation were reported for the first time. At that time, the causes of this new kind of pneumonia were unknown; patients were diagnosed with apparent symptoms of fever, dry cough, and respiratory issues. After taking samples from the patients, "Chinese Centre for Diseases Control and Prevention declared it as Severe Acute Respiratory Syndrome Coronavirus-2 (SARS-Cov-2)" (Sohrabi et al., 2020, p. 71). Later, World Health Organization (WHO) named the disease as Covid-19, and, on January 30, 2020, it declared the outbreak of Covid-19 as Public Health Emergency of International Concern (PHEIC). In addition to curtailing the spread of the virus and determining its clinical impact, one primary objective of PHEIC was to ensure minimizing the socio-economic cost of Covid-19 and to stop the spread of false information that may cause international chaos (Velavan \& Meyer, 2020). World leaders immediately responded to emergency declaration by putting various preventive measures in place like lockdowns, closure of flight operations to stop international transmission of the virus, isolation of the infected people, provision of financial resources to support health systems etc. (Bull, Al-Ansari, Biddle, Borodulin, Buman, Cardon, \& Willumsen, 2020). At the start of the outbreak, there was a dearth of knowledge regarding Covid-19. A community of researchers across various disciplines responded to this challenge of knowledge scarcity accordingly, and initiated research efforts to furnish sufficient knowledge about the origin, causes and consequences of
Covid-19 (Remuzzi \& Remuzzi, 2020; Mugrabi, Rozner, \& Peles, 2020).

Humans have witnessed virus attacks at different points of history, in various forms, like SARS (Severe Acute Respiratory Syndrome) in 2002; Southern China, MERS (Middle East Respiratory Syndrome) in 2012; Saudi Arabia and the Middle East and recently Covid-19 at the end of November 2019 in China (Meo et al., 2020). The origin of all these viruses have been similar, as they originated in animals and from there got transmitted to human through contact. For instance, it was found that MERS was transmitted from camels to humans, SARS from bats, cats and civet to humans and Covid-19 from bats and sea animals to humans. Though there have been many studies in this regard, but still, there are no conclusive findings regarding the biology of these viruses (Wang, Tang, \& Wei, 2020). It is beyond the context of this study to discuss the biological characteristics; nevertheless, there are many recent studies in the field of medical and biological sciences to this end.

Viruses have always caused serious health issues to humans and the diseases owing to them have posed social and economic challenges (Kagaayi \& Serwadda, 2016). Corona Virus (Covid-19) is becoming more deadly to humans, and till this point of time, the world has witnessed a number of 4.35 million confirmed cases of the affectless of the virus and about 0.297 million deaths. By now, it has reached to 187 countries and continues crossing their borders. Strangely, countries with improved health systems like the USA, UK, Italy, France, and Germany are more effected vis-à-vis the less developed countries of the world (Volpato, Landi, \& Incalzi, 2020). Covid-19 outbreak is considered a collective challenge for the world community. Recently, on May 13, 2020, WHO doubted that the virus might prevail forever, and perhaps, the new arrangements could not be sufficient to curtail its spread. There is a need for a collective response because of the rapid spread of the Covid-19. The changing statistics, and new findings are heightening the international concerns (Sohrabi et al., 2020). This is not only the responsibility of medical and biological scientists to exert more research efforts, but social scientists are equally responsible for evaluating the socio-economic impact of the pandemic. In this regard, our study contributes towards the global list of efforts directed to curtail Covid-19.

\section{Perceived Stress}

Stress is a common phenomenon experienced by individuals in their daily life. Generally, stress refers to one's response to an adverse change in external circumstances or to threatening situations. Humans respond to external events which disturbs their status of complacency. This response can be explicit or implicit. The understandable response is exhibited through behaviour, while implicit response causes mental disturbance. 
In the field of Psychology, stress is defined as one's feelings of mental distress and tension (Shahsavarani, Azad Marz Abadi, \& Hakimi Kalkhoran, 2015). For this study, we define stress as under:

"Stress is a bodily response to a change which needs a response, regulations both physical, and psychological or emotional adaptation. Stress could derive from any situation, condition, thought, or state which may result in frustration, anger, nervousness, and anxiety" (Shahsavarani et al., 2015).

Individuals can experience different levels of stress following the severity of the external situation. Lower stress level may be desirable as it promotes healthy behaviour and vice versa. Stress can be positive, as well as, harmful. Positive stress improves psychological health, enhances performance, instills motivation, allows individuals to respond to external situation and facilitates positive adaptability to a situation (AL-Abrrow, Al-Maatoq, Alharbi, Alnoor, Abdullah, Abbas, \& Khattak, 2011; Makhubela, 2020). Positivity and negativity of stress are dependent on how the individuals' perception system interprets the stress factors. Individuals experience stress owing to the complexity of human interaction with the surrounding environment. Though it is a permanent feature of human life to experience stress but continuously increasing stress can always pose a threat to physical and psychological health (Mirela \& Madalina-Adriana, 2011).

Perceived stress refers to one's feeling of how much one is stressed at a given point of time. Naturally, it is one's perception of the level of stress that one is experiencing, owing to some external threatening situation. Stress perception is mostly dependent on socio-cultural factors that vary across situations (Lim, Tam, \& Lee, 2013). Cohen et al. (1994) developed a Perceived Stress Scale, which is a widely used tool for psychological measurement of perceived stress. It determines the extent to which a situation can be regarded as stressful for an individual. It determines individuals' responses concerning uncontrollable, unpredictable, and undesirable situations.

Higher levels of perceived stress bear negative consequences for individuals, and result in a multitude of psychological problems like depression, anxiety, and disturbed metabolism. (Quick, Horn, \& Quick, 1987) (Al-Dubai, AlNaggar, Alshagga, \& Rampal, 2011, p. 57). A controllable level of perceived stress is considered positive and helps individuals to develop their skills for coping with stressful situations. On the contrary, higher levels of stress can damage immune functions to respond appropriately. It is widely known that perceived stress usually harms physical health, mental health and growth (Cohen, 1996).

There are four different concepts to study stress or perceived level of stress, which are, stimulus concept, response concept, discrepancy concept and transactional concept (Brief
\& George, 1995). Stimulus concept places emphasis over situational factors i.e. there are certain stimuli which cause a stressful situation, for example, workplace conflict. Different individuals respond differently to a given stimulus. Response concept states that there is always a psychological response to perceived stress. Stress is an individual specific reaction, irrespective of the nature of a given situation. Discrepancy concepts defines stress as a discrepancy and incongruence between what a person desires and what a given situation offers (Brief \& George, 1995). Shahsavarani et al., 2015, p.232) discussed 'transactional-cognitive process' approach (transactional concept) to study perceived stress. They argued that perceived stress refers to a specific relation between humans and their surrounding situation, where they find an incompatibility between the demands of the surrounding situation and the resources available and, hence leads to endangering their wellbeing. The higher the gap between the demands and the resources, the higher is the level of perceived stress and thus this relation is actional. It is considered as 'an active and progressive process which includes causal antecedents, intervening processes, and influence' (Shahsavarani et al., p.232).

In recent times, stress (perceived stress) has become an essential consideration within organizational context, because it is considered pertinent to the organizational as well as the employees' performance (Prasad, Vaidya, \& Anil Kumar, 2018). This is also known as occupational stress. Occupational stress has detrimental impact in terms of employees' physical and psychological health and undermines organizational goals (Sonnentag \& Frese, 2003). Occupational stress is caused when employees confront a job that does not align with their skills and familiarity and challenge their capability to meet the demands of the job. Increased work pressure, resources inadequacy, lack of recognition and support, role ambiguity, longer working hours and work-family conflict expose employees to a heightened level of perceived Occupational Stress. This affects employees negatively, draining them of their energies by causing job burnout. Job burnout is physical, emotional, and psychological exhaustion triggered by extended exposure to Occupational Stress (Mirela \& Madalina-Adriana, 2011). It has been found that perceived Occupational Stress among medical staff caused them extended absence from work. It has also been revealed that perceived occupational stress is directly linked to mental health issues. There is evidence of perceived occupational stress incurring heavy costs (both financial and non-financial, i.e. physical, and emotional exhaustion) both to the organization and its employees. For example, a study involving more than 46,000 employees of US companies revealed that companies bear $46 \%$ more cost to take care of the employees having higher levels of perceived organizational Stress (Goetzel, et al., 1998). 


\section{Health Climate}

The concept of health climate goes way back to the concept of 'social climate'. Stokols stated that health and health behavior of an organization are affected by the social structure of that organization (Stokols, 1992, p. $8)$. The social climate is described in terms of "climate for health" (Ilgen, 1990, p. 275), and "wellness-oriented workplace. The objective is to promote healthy work norms, aimed at ensuring employees' health and wellbeing (Mearns, Hope, Ford, \& Tetrick, 2010). Health climate of organization refers to its employees' perception of organizational support for their physical and psychological health. It includes an organization's health norms and practices, different intervention programs, health-related facilities and workplace conditions (Liu, Raza, Zhang, Zhu, \& Gul, 2020b; Zweber, Henning, \& Magley, 2016).

Organization's health climate has been an essential facet of organizational research, and organizational scholars have always underscored the importance of employees' health, because it is an essential determinant of workplace behavior and organization's performance (Sonnentag, 2015). Employees' lower health can always incur high costs to the organization (Danna \& Griffin, 1999). Organization's health climate not only directly affects employees' health but also has a telling upon the employees', as well as their leaders' behaviors and thoughts, leading to wholesome workplace environment (Schneider \& Becker, 2005). Organization's health climate promotes 'healthpromoting leadership' (AL-Abrrow, Abdullah, \& Atshan, 2019a). Health promoting leadership aims at providing health support to its employees, addressing employees' mental health issues and encouraging their participation in promoting healthy workplace (Franke, Felfe, \& Pundt, 2014). It shows that organizations have prioritized employees' health issues as an essential organizational agenda. An organization, with higher commitment to health climate, facilitates employees in terms of ample resources provision to them, so that they remain healthy and consequently demonstrate healthy work behaviour. Contrary to this, an organization with lesser concern for employees' health and wellness has to face frequent employees' turnover, lesser organizational commitment and lower productivity (Schneider \& Becker, 2005).

Some critical dimensions of health climate include perceived supervisory care, perception of work authority, and flexible working hours. All this allows employees to participate in workplace health promotion programs effectively. Health climate has been closely related to employees' physical and psychological well-being. It has been found that the health climate not only promotes healthy behaviors among employees but also increases their job satisfaction, organizational commitment, and efficiency. Health climate has also been found to mitigate work stress and other psychological issues of employees (Zweber et al., 2016) .

In the same way, a healthy workplace can benefit not only the employees by reducing their stress and solving their other work issues, but also lowers employees' turnover, enhances organization's performance, and increases customer's satisfaction. Organizations need to take of care of their health climate, because it helps organizations to sufficiently cut their costs related to poor employees' health, such as longer absenteeism and low productivity (Carls et al., 2009). There is ample evidence that there are organizations which sufficiently invest in support programs to better their employees' physical and psychological well-being and to avoid the high associated costs (Grawitch, Gottschalk, \& Munz, 2006) .

There are three important facets of organization's health climate i.e. "workgroup facet, supervisor facet and organizational facet" (Zweber et al., 2016, p. 255). Workgroup facet refers to perceived care for health from immediate workgroup members. Because of closer interaction within a group, co-workers are a significant source of support. It has been found that continuous support from group members is instrumental to employees' both physical and psychological well-being and mitigates jobrelated stress. Supervisor facet of health climate is also an essential consideration because supervisors have a significant influence on workplace interventions aimed at employees' well-being. A negative opinion of the supervisor about the intervention program, for example, may hamper the success of such intervention. Supervisors' emotional and social support is a preventive measure to reduce job stress and thus promote employees' well-being (Fiernaningsih, 2020). A third important facet of health climate refers to perceived organizational support through programs and policies, such as, health insurance, which fosters employees' health. Organizations ensure availability of adequate resources to support employees' health program (Zweber et al., 2016).

There is a need to understand the difference between a healthy climate and a safety climate. Previously, the concept of health climate has been discussed in safety climate literature, because both are deemed to be one construct (Bjerkan, 2010); however, recent literature makes an essential distinction between them. Safety climate is primarily concerned with safe practices and procedures to avoid workplace injuries. It relates to workplace accidents, injuries, and other relevant precautionary measures. Workplace health climate is a broader concept that goes beyond avoiding workplace injuries; rather, it induces safe work behaviors and refers to employees' health at work and off work. It is featured with work norms, resources and workplace interventions related to employees' well-being. Previously, it has been established that health climate is closely related to worksites characteristics like ban on smoking, promoting workout and 
healthy diet plans, whereas, safety climate is concerned with worksites safety measures, such as protection of employees from work-related injuries (Mearns et al., 2010).

\section{Covid-19 and Perceived Stress}

Immediately after the outbreak of Covid-19, there have been continuous research efforts to understand its nature, causes and consequences. One primary concern of the researchers is to address the physical and psychological issues being faced by medical workers (AL-Abrrow, Alnoor, Ismail, Eneizan, \& Makhamreh, 2019b). This is because medical workers are more exposed and vulnerable to the pandemic, as they come in direct interaction with patients and suspectedly infected co-workers (Sim, 2020). During Covid-19, medical workers across the globe have faced an increase in their workload, longer working hours and a higher level of psychological and physical stress. A recent study has reported that because of direct exposure to Covid-19, medical workers have been found to have developed a higher level of stress in the form of psychological distress (Shanafelt et al., 2020). Similar findings were reported by previous studies on SARS and MERS stating that medical workers developed higher stress levels that caused post-traumatic disorder (Meo et al., 2020). It has been witnessed that a number of medical workers have got infected and have gone on self-quarantine. This is causing a decrease in the number of medical workers to deal with patients and is resulting in more work burden and mental stress on those who are available to serve the patients. Extra workload can emasculate medical workers' ability to combat pandemic and can prompt various stress-related issues, for example, anxiety, fear, social isolation from family, depression, and discrimination (AL-Abrrow et al., 2019b). It has been found that there are four major risk factors that cause psychological stress among medical workers and these include perception of getting infected, the impact of the virus on their work performance, depression and unsafe working conditions (Styra et al., 2008). A recent study of medical staff in China has reported that health workers faced mental issues during the Corona pandemic. The same study also found that the risk of getting infected and the risk of transmitting the virus to their families is a major reason for psychological distress among medical staff. It was also found that medical staff develops stress when they see their colleagues in stress. Medical staff is reported to have experienced less stress when they were sure that their families were not infected (Cai et al., 2020). Psychological distress is a kind of stress and refers to an individual' emotional state characterized by sadness, anxiety, depression and loss of interest etc. (Drapeau, Marchand, \& Beaulieu-Prévost, 2012).

The above discussion leads us to conceive the following hypothesis.

$\boldsymbol{H}_{1}$ : Medical workers in Pakistan develop additional forms of perceived stress due to Covid-19 pandemic

\section{Health Climate as a Moderator}

As stated earlier, that organization's health climate refers to organization health norms and practices, different intervention programs, health-related facilities, and workplace conditions. Research findings reveal that health climate mitigates or aggravates the stress and other psychological issues of employees. There are organizational factors like safety and health management that moderate the mental stress effect of Covid19 on health workers (Zweber et al., 2016). Studies have found that specific objective measures, like introduction of shift engagement, induction of more medical staff, provision of sufficient facilities like safety dress, safe and clean working condition, and adoption of proper policies and protocols can help medical workers to cope with the perceived stress (Gavin, Hayden, Adamis, \& McNicholas, 2020). Similarly, recognizing and appreciating the efforts and services of the medical workers by the hospital management, government and civil society can boost their morale and reduce their stress level (Hamouche, 2020). It has been reported that postpandemic psychological issues diagnosed among medical staff are often more serious than their physical problems (Alnoor, 2020; Alnoor, Al-Abrrow, Abdullah, \& Abbas, 2020). Psychological counselling can help medical staff to overcome post-pandemic psychological issues (Lai, Ma, Wang, Cai, Hu, Wei, \& Hu, 2020). In another study, it has been found that psychological counselling can significantly help to overcome mental stress of nursing staff (Rana et al., 2020). A study conducted to address mental health care of the medical staff at The Second Xiangya Hospital, China, revealed that medical workers were provided with a separate space in the hospital to take rest, quality food and other necessities of life. The recorded videos of medical workers were sent to their families in order to pacify them. Hospital also arranged for the provision of requisite knowledge of the disease, and protective equipment, in addition to deputing security staff for helping medical workers in dealing with problematic patients. Hospital also introduced and implemented guidelines on the usage of available facilities. Some relaxing activities were initiated at the hospital to help medical workers reduce their stress. More importantly, psychologists were hired who visited the hospital at regular intervals to sit with the medical workers and to listen to their stories of their difficult times and to provide counselling accordingly. All these measures at The Second Xiangya Hospital, China helped to sufficiently reduce the level of stress among medical workers (Chen et al., 2020).

Contrary to the above, lack of proper facilities, for example, under-staffing, lack of protective measures, unavailability of proper equipment and medicine, and no indemnity to safeguard one's family from getting affected from the virus put further psychological burden on medical workers (Aymen, Alhamzah, \& Bilal, 2019; Babore et al., 2020). These issues 
negatively affect the psychological well-being of medical workers, and as a result they fall victim to more significant mental stress (Greenberg, Docherty, Gnanapragasam, \& Wessely, 2020). It was found that the absence of a mental health system and a lack of trained psychologists caused heightened stress among medical workers during the outbreak of Ebola (Li et al., 2015). It has been argued that moderating effect of organization's health climate has been not explored adequately and hence needs more research attention (Xiang et al., 2020).

From the above-cited literature, it can be hypothesized that:

$\boldsymbol{H}_{2}$ : Health climate moderates the effect of perceived stress caused by Covid-19 among medical workers in Pakistan.

$\boldsymbol{H}_{2 a}:$ Health climate offered by workgroup moderates the effect of perceived stress caused by Covid-19 among medical workers in Pakistan.

$\boldsymbol{H}_{2 \boldsymbol{b}}$ : Health climate by offered supervisor moderates the effect of perceived stress caused by Covid-19 among medical workers in Pakistan.

$\boldsymbol{H}_{2 c}:$ Health climate by offered organization moderates the effect of perceived stress caused by Covid-19 among medical workers in Pakistan.

Figure 1 shows the model of the study:

\section{Method}

\section{Sample and Procedures}

Medical workers (doctors, nurses, paramedics etc.) dealing with Covid-19 patients directly in different hospitals of Pakistan constitute the population of this study. Due to restricted physical access to the respondents owing to the existence of the epidemic, online questionnaire was the chosen as being the most appropriate to access the sample in the given circumstances. An online questionnaire was designed (by Google Form). Due to the obstacles involved in delivering the paper form physically to the individuals of the sample, social media groups of the target respondents (health workers) available on social media sites (such as WhatsApp and Facebook) were also utilized. Through them, the link of the online questionnaire was sent to these groups for the purpose of filling the questionnaires. The questions included in the online questionnaire were sent in the form of an electronic link that could be opened on a smart phone or computer and could be answered instantly. The access was obtained through informed consent and cooperation with officials of the targeted hospitals. In the end, 261 responses were obtained, out of which 255 were valid for statistical analysis. The characteristics of the respondents are given in Table 1.

\section{Measurement}

Effects of Covid-19 It is a large family of viruses that may cause illness in animals and humans, besides affecting a person not only physically through respiratory infections but also socially and economically. A five-dimensional scale was developed based on the elements that have frequently been experienced or contemplated by medical workers, especially during crises (depending on the opinions of specialists and workers in the health sector). The tool for this variable was adapted on the basis of the study conducted by Cai, Tu, Ma, Chen, Fu, Jiang, \& Zhuang, (2020) and Gray-Toft and Anderson (1981). The dimensions included are Death and dying, Inadequate Preparation, Uncertainty concerning treatment, Workload, and Expected Reward. The test was framed to check five dimensions on the basis of 19 items, with four items each to get feedback on the four dimensions and three items on the fifth dimension The workers' response was according to the five-point Likert scale, ranging from not strongly agreeing to strongly agreeing, on the basis of what they experienced during the period of the pandemic in hospitals. The scale is reported to have good reliability and validity (Cronbach's $\alpha$ was estimated at .81).

Perceived Stress It is the individual's response to an adverse change in external circumstances or to threatening situations, and this response is recorded through the human feeling of anxiety, which affects human beings psychologically and physically. The PSS-10 scale developed by Cohen et al. (1994) was used for measuring perceived stress. This scale

Fig. 1 Model of study

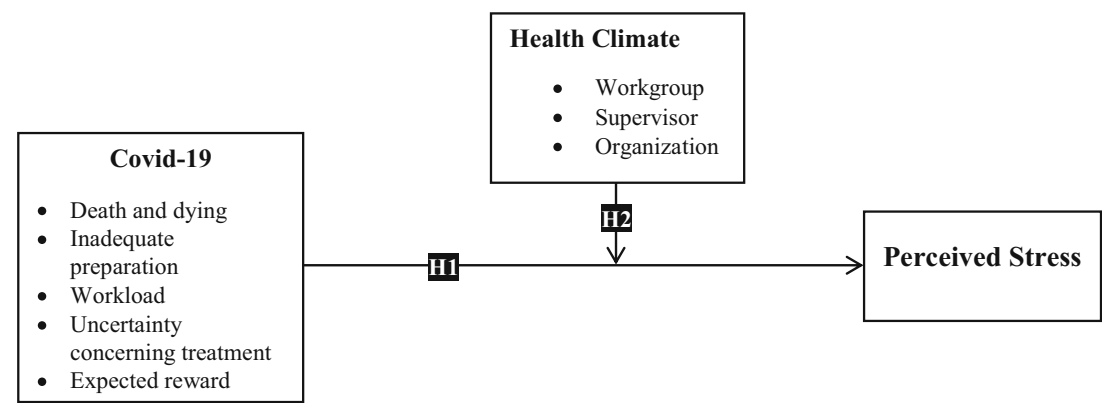


Table 1 Characteristics of Sample

\begin{tabular}{|c|c|c|c|c|c|}
\hline Age & $\mathrm{N}$ & $\%$ & Gender & $\mathrm{N}$ & $\%$ \\
\hline 25 or below & 120 & $47.06 \%$ & Female & 90 & $35.29 \%$ \\
\hline $26-35$ & 78 & $30.59 \%$ & Male & 165 & $64.71 \%$ \\
\hline $36-45$ & 36 & $14.12 \%$ & Total & 255 & $100 \%$ \\
\hline $46-55$ & 15 & $5.88 \%$ & Nature of Job & $\mathbf{N}$ & $\%$ \\
\hline $56 \&$ above & 6 & $2.35 \%$ & Doctor & 96 & $37.65 \%$ \\
\hline \multirow[t]{3}{*}{ Total } & \multirow[t]{3}{*}{255} & \multirow[t]{3}{*}{$100 \%$} & Nurse & 144 & $56.47 \%$ \\
\hline & & & Others & 15 & $5.88 \%$ \\
\hline & & & Total & 255 & $100 \%$ \\
\hline Qualification & $\mathbf{N}$ & $\%$ & Experience & $\mathbf{N}$ & $\%$ \\
\hline Bachelor/MBBS & 102 & $40.00 \%$ & 3 or less than 3 years & 108 & $42.35 \%$ \\
\hline M.Phil/PHD & 30 & $11.76 \%$ & $3-5$ years & 51 & $20.00 \%$ \\
\hline Nursing Diploma/Diploma & 84 & $32.94 \%$ & $5-10$ years & 27 & $10.59 \%$ \\
\hline Secondary/Higher Secondary & 33 & $12.94 \%$ & $10-15$ years & 24 & $9.41 \%$ \\
\hline Others & 6 & $2.35 \%$ & $15 \&$ above & 45 & $17.65 \%$ \\
\hline Total & 255 & $100 \%$ & Total & 255 & $100 \%$ \\
\hline
\end{tabular}

was adopted as it was in agreement with the purpose of the study (i.e. recording perceived stress caused by dealing with Covid-19 cases in hospitals). The response was based on the workers' own reports of their first-hand experience of perceived stress at work, during the pandemic period (5-point Likert scale). The reliability and validity of the scale were found good (Cronbach's was estimated at .78).

Health Climate It is a "wellness-oriented workplace" to promote healthy work standards aimed at improving employees' health and well-being. A 9-item scale was used to measure the moderator variable (Zweber et al., 2016). It consisted of three dimensions, i.e. health climate provided by workgroup, which was based on 2 items; health climate provided by supervisor, which was based on 3 items: and health climate provided by the organization, which was based on 4 items. The response was based on the workers impression of the health climate available inside the hospitals and work environment, which was to be graded by them on a 5-point Likert scale. The scores of the scale showed excellent validity, whereas the reliability of the scale was estimated to be at 0.85 .

\section{Results}

\section{Descriptive Statistics and Correlation}

Table 2. presents the means, standard deviations (SD), and correlation coefficients between the variables. All means are at an average level (3.07-2.58), while the mean for perceived stress has the largest value. The SD values were all acceptable, indicating little dispersion in the responses. The correlation coefficient between major and minor variables, most of which were significant, indicated initial support for the study hypotheses. The correlation coefficients did not suggest any problems of multi-collinearity, as all correlation coefficients were less than 0.70 (Gerbing, \& Anderson, 1988).

\section{Convergent and Discriminant Validity}

Convergent and discriminant validity were used to ensure the validity of the constructs for each scale. Convergent validity can be assessed using three indices, namely factor loadings, construct reliability (CR), and average variance extracted (AVE) (Fornell \& Larcker, 1981). The factor loading is supposed to exceed 0.5 (or it should exceed 0.7 in ideal conditions). The AVE is supposed to exceed 0.5, and the CR, Cronbach's $\alpha$, needs to be higher than 0.7 (Hair, Black, Babin, \& Anderson, 2009). Table 3. shows that all the results were acceptable, indicating the convergence validity for all scales.

Discriminate validity indicates the extent of the discrepancy between two scales designed to measure two different theoretical concepts (Hatcher, 1994). Because the health climate variable, as shown in the results in Table 2, has a negative correlation with the other two variables, it was excluded here because it would undoubtedly have been discriminant. Therefore, this test was conducted on the independent variable (Covid-19 and its five dimensions), and the dependent variable (perceived stress), especially in light of the convergence of the two concepts theoretically, so as to make us utterly unsure about the differentiation of their measures. Evidence for the existence of discriminant validity is that when the AVE of each of the two variables is higher than the squared correlations (SC) between them (Hair et al., 2009). 
Table 2 Descriptive statistics and correlation

\begin{tabular}{|c|c|c|c|c|c|c|c|c|c|c|c|c|c|}
\hline \multicolumn{2}{|c|}{ Variables } & \multirow{2}{*}{$\begin{array}{l}\text { Mean } \\
3.00\end{array}$} & \multirow{2}{*}{$\begin{array}{l}\mathrm{SD} \\
.86\end{array}$} & \multirow[t]{2}{*}{1} & \multirow[t]{2}{*}{2} & \multirow[t]{2}{*}{3} & \multirow[t]{2}{*}{4} & \multirow[t]{2}{*}{5} & \multirow[t]{2}{*}{6} & \multirow[t]{2}{*}{7} & \multirow[t]{2}{*}{8} & \multirow[t]{2}{*}{9} & \multirow[t]{2}{*}{10} \\
\hline 1 & Death and dying & & & & & & & & & & & & \\
\hline 2 & Inadequate preparation & 3.07 & .88 & $.446^{* * *}$ & & & & & & & & & \\
\hline 3 & Workload & 2.65 & .89 & $.340^{* *}$ & $.369^{* *}$ & & & & & & & & \\
\hline 4 & Uncertainty concerning treatment & 2.68 & .83 & $.381^{* *}$ & $.337^{* *}$ & $.237^{* *}$ & & & & & & & \\
\hline 5 & Expected reward & 2.88 & 1.02 & $.140^{*}$ & $.283^{* *}$ & $.393^{* *}$ & $.437^{* *}$ & & & & & & \\
\hline 6 & Workgroup & 2.58 & 1.09 & -.100 & -.070 & -.093 & $-.158^{*}$ & -.099 & & & & & \\
\hline 7 & Supervisor & 2.77 & .74 & $-.129^{*}$ & -.097 & -.038 & .030 & .001 & $.261^{* *}$ & & & & \\
\hline 8 & Organization & 2.93 & .97 & -.010 & -.061 & $-.180^{* *}$ & -.040 & -.078 & $.526^{* *}$ & $.479^{* *}$ & & & \\
\hline 9 & Covid-19 & 2.86 & .61 & $.656^{* * *}$ & $.605^{* *}$ & $.686^{* *}$ & $.689^{* * *}$ & $.686^{* *}$ & $-.151^{*}$ & -.067 & -.109 & & \\
\hline 10 & Health Climate & 2.76 & .74 & -.097 & -.094 & $-.138^{*}$ & -.085 & -.083 & $.611^{* *}$ & $.672^{* *}$ & $.857^{* *}$ & $-.145^{*}$ & \\
\hline 11 & Perceived Stress & 2.97 & .71 & $.429^{* * *}$ & $.187^{* * *}$ & $.297^{* * *}$ & $.350^{* * *}$ & $.169^{* *}$ & .031 & $-.147^{*}$ & .035 & $.411^{* * *}$ & -.018 \\
\hline
\end{tabular}

Note: $*: p<.05 ; * *: p<.01$

Based on the data given in Tables 2 and 3, we obtained results that are shown in Table 4. The results show that the AVE values are higher than the SC values for each pair of variables that are meant for measuring a different sub-concept, and indicate discriminant validity for all scales.

\section{Testing the Hypotheses}

To test the two main hypotheses and the sub-hypotheses, multiple hierarchical regression was used in the SPSS program. Variables were entered in three models. The first model is meant for testing the first hypothesis, the second model is meant for testing the second hypothesis, and finally, the third model is meant for testing the sub-hypotheses. Table 5 contains the results obtained.

Results suggest that medical workers develop stress due to Covid-19, which in line with the first hypothesis. Also, the results indicate that there is a moderating role played by a healthy climate in increasing this effect, i.e. acceptance of the second hypothesis. As for the sub-hypotheses, the results indicate that role of health climate provided by supervisor decreases the positive impact of Covid-19 on perceived stress. Contrary to the other two dimensions of health climate, this third one was not found.

\section{Discussion}

Our results show a positive impact of Covid-19 on perceived stress experienced by medical workers dealing with Covid-19 virus. The nature of this disease is frightful enough to make medical workers stressed and anxious while dealing with it directly in workplace (Abid et al., 2020; Qureshi et al., 2020). The pandemic has caused stress among medical workers both at work and off work, especially, when they are conscious of the fact that there are higher chances that they might not only contract the virus but may also become the source of transmitting it to their immediate family members (see: Nanjundaswamy et al., 2020). Our findings reveal that the role of health climate, which was supposed to reduce this stress, acted oppositely (Gavin et al., 2020). The only exception to this was borne by the results of the sub-hypotheses that showed that, supervisors, (unlike the workgroup or organization), have an essential role in reducing stress among the workers, the fallout of Covid-19 has made the medical workers feel themselves more vulnerable, which negatively affects their job satisfaction and leads to heightening their workplace stress (Podder, Agarwal, \& Datta, 2020). Medical workers have differing views on fear and complacency regarding their work in the health sector (AL-Abrrow et al., 2020). Satisfaction for them appears to stem from their core values. Fear may push medical workers to leave work. Employees who intend to leave face the problem of less support, recognition and appreciation of their work (Liu, Lithopoulos, Zhang, GarciaBarrera, \& Rhodes, 2020a). This is in line with the assumption that negative perceptions of individuals negatively affect business outcomes when the employee believes the environment as inappropriate for work. Thus, this confirms the negative psychological and physical effects developed by the health staff dealing with patients of Covid-19 in the health sector (see: Abid et al., 2020; Flesia et al., 2020; Zandi et al., 2020).

This study, subsidiary to its prime objectives, also found out some positive aspects such as the value and meaning of work in the health sector. If rightly highlighted and emphasized it may help medical workers to perform their work effectively. The results of the study show negative consequences that that run counter to the goals of organization. Therefore, if medical workers increase their self-efficacy, this will reduce the negative consequences of work stress and increase the attractiveness of the organizational climate. It will also enhance the sense of power 
Table 3 Convergent validity

\begin{tabular}{|c|c|c|c|c|c|}
\hline Factors & Items & factor loading & AVE & $\mathrm{CR}$ & Cronbach's $\alpha$ \\
\hline \multirow[t]{4}{*}{ Death and dying } & 1 & $.793^{* *}$ & \multirow[t]{4}{*}{.544} & \multirow[t]{4}{*}{.722} & \multirow[t]{4}{*}{.808} \\
\hline & 2 & $.735^{* *}$ & & & \\
\hline & 3 & $.608^{* *}$ & & & \\
\hline & 4 & $.798^{* *}$ & & & \\
\hline \multirow[t]{4}{*}{ Inadequate preparation } & 5 & $.735^{* *}$ & \multirow[t]{4}{*}{.539} & \multirow[t]{4}{*}{.716} & \multirow[t]{4}{*}{.799} \\
\hline & 6 & $.752^{* *}$ & & & \\
\hline & 7 & $.718^{* *}$ & & & \\
\hline & 8 & $.731^{* *}$ & & & \\
\hline \multirow[t]{4}{*}{ Workload } & 9 & $.691^{* *}$ & \multirow[t]{4}{*}{.539} & \multirow[t]{4}{*}{.715} & \multirow[t]{4}{*}{.790} \\
\hline & 10 & $.769^{* *}$ & & & \\
\hline & 11 & $.630^{* * *}$ & & & \\
\hline & 12 & $.830^{* *}$ & & & \\
\hline \multirow[t]{4}{*}{ Uncertainty concerning treatment } & 13 & $.734^{* *}$ & \multirow[t]{4}{*}{.539} & \multirow[t]{4}{*}{.716} & \multirow[t]{4}{*}{.805} \\
\hline & 14 & $.711^{* *}$ & & & \\
\hline & 15 & $.717^{* * *}$ & & & \\
\hline & 16 & $.773^{* * *}$ & & & \\
\hline \multirow[t]{3}{*}{ Expected reward } & 17 & $.795^{* *}$ & \multirow[t]{3}{*}{.618} & \multirow[t]{3}{*}{.750} & \multirow[t]{3}{*}{.851} \\
\hline & 18 & $.809^{* * *}$ & & & \\
\hline & 19 & $.753^{* *}$ & & & \\
\hline \multirow[t]{2}{*}{ Workgroup } & 20 & $.821^{* *}$ & \multirow[t]{2}{*}{.659} & \multirow[t]{2}{*}{.719} & \multirow[t]{2}{*}{.809} \\
\hline & 21 & $.803^{* *}$ & & & \\
\hline \multirow[t]{3}{*}{ Supervisor } & 22 & $.740^{* *}$ & \multirow[t]{3}{*}{.599} & \multirow[t]{3}{*}{.729} & .821 \\
\hline & 23 & $.767^{* *}$ & & & \\
\hline & 24 & $.814^{* *}$ & & & \\
\hline Organization & 25 & $.864^{* *}$ & .605 & .788 & .895 \\
\hline & 26 & $.739^{* * *}$ & & & \\
\hline & 27 & $.718^{* * *}$ & & & \\
\hline & 28 & $.782^{* *}$ & & & \\
\hline Perceived Stress & 29 & $.749^{* *}$ & .507 & .825 & .808 \\
\hline & 30 & $.664^{* * *}$ & & & \\
\hline & 31 & $.624^{* *}$ & & & \\
\hline & 32 & $.762^{* *}$ & & & \\
\hline & 33 & $.746^{* *}$ & & & \\
\hline & 34 & $.818^{* * *}$ & & & \\
\hline & 35 & $.746^{* *}$ & & & \\
\hline & 36 & $.510^{* *}$ & & & \\
\hline & 37 & $.743^{* *}$ & & & \\
\hline
\end{tabular}

Note: $* *=p \leq 0.01$

and capacity of medical workers to improve the image of the organization and gain motivation to act, which is in agreement with previous studies (Mehta, \& Sivadas, 1995; Remuzzi \& Remuzzi, 2020). It is concluded that employees' perceptions of Covid-19 have a direct impact on the development of work stress among medical workers; Besides, health climate plays a mediating role between the health workers' perception of Covid-19 and perceived stress and thus leads to mitigating the impact of Covid19. This is in line with the findings of other studies (e.g., Sheehan \& Fox, 2020; Watson, Bacigalupe, Daneshpour, Han, \& ParraCardona, 2020).

\section{Theoretical Implications}

The Literature suggests that it is obligatory to discover those factors that increase job stress in health institutions, and to discover appropriate mechanisms to reduce this stress. This necessity is felt after considering the consequences of stress in the form of physical and psychological exhaustion, which in turn can endanger human health (AL-Abrrow et al., 2020; Liu, Lithopoulos, et al., 2020a). Many of the mechanisms that prestigious health institutions use to reduce stress among their staff include financial incentives, healthy and safe climate, 
Table 4 Discriminant validity

\begin{tabular}{|c|c|c|c|c|c|c|c|c|}
\hline \multicolumn{2}{|c|}{ Variables } & \multirow{2}{*}{$\begin{array}{l}1 \\
-\end{array}$} & \multirow{2}{*}{$\begin{array}{l}2 \\
.541\end{array}$} & \multirow{2}{*}{$\begin{array}{l}3 \\
.541\end{array}$} & \multirow{2}{*}{$\begin{array}{l}4 \\
.541\end{array}$} & \multirow{2}{*}{$\begin{array}{l}5 \\
.581\end{array}$} & \multirow{2}{*}{$\begin{array}{l}6 \\
.550\end{array}$} & \multirow{2}{*}{$\begin{array}{l}7 \\
.526\end{array}$} \\
\hline 1 & Death and dying & & & & & & & \\
\hline 2 & Inadequate preparation & .199 & - & .539 & .539 & .578 & .547 & .523 \\
\hline 3 & Workload & .116 & .136 & - & .539 & .578 & .547 & .523 \\
\hline 4 & Uncertainty concerning treatment & .145 & .114 & .056 & - & .578 & .547 & .523 \\
\hline 5 & Expected reward & .020 & .080 & .154 & .191 & - & .587 & .563 \\
\hline 6 & Covid-19 & .430 & .497 & .471 & .475 & .471 & - & .532 \\
\hline 7 & Perceived Stress & .184 & .035 & .088 & .123 & .029 & .169 & - \\
\hline
\end{tabular}

Note: The values in the upper right represent AVE, while the numbers in the bottom left represent SC

organizational support, and decisive leadership. These tools have proven effective in relieving job stress. However, in developing countries, health institutions lack the culture of recognizing employees as a valuable resource to invest in (AlAbrrow, 2014; Zweber et al., 2016). Lesser investment in the provision of health climate and less awareness among medical workers cause job stress (Georgiou, Delfabbro, \& Balzan, 2020). Many of the workplace factors, for example, loss of control over treatment procedures due to inadequate physical facilities, lack of awareness of epidemic treatment, fewer or no expectation of rewards or material and moral incentives, contribute to cause and increase perceived stress among medical workers. Therefore, the provision of adequate facilities, along with incentives, can help medical workers to reduce their perceived stress.

Table 5 Hypotheses test of study

\begin{tabular}{lccc}
\hline Variables & \multicolumn{2}{c}{ Dependent Variable: Perceived Stress } \\
\cline { 2 - 4 } & Model 1 & Model 2 & Model 3 \\
\hline Covid-19 & $0.411^{* * *}$ & 0.027 & 0.002 \\
Health Climate & & $-0.341^{*}$ & $-0.221^{*}$ \\
Covid-19*Health Climate & & $0.591^{*}$ & 0.091 \\
Workgroup & & & -0.149 \\
Supervisor & & & $-0.213^{* *}$ \\
Organization & & & -0.174 \\
Covid-19*Workgroup & & & -0.144 \\
Covid-19*Supervisor & & & $-0.110^{*}$ \\
Covid-19*Organization & & & -0.084 \\
R & 0.411 & 0.434 & 0.493 \\
R Square & 0.169 & 0.188 & 0.243 \\
Adjusted R Square & 0.166 & 0.178 & 0.224 \\
F value & $51.455^{* * *}$ & $19.364^{* * *}$ & $13.273^{* * *}$ \\
\hline
\end{tabular}

Note: $*: \mathrm{p}<.05 ; * *: \mathrm{p}<.01 ; * * *: p<.001$

\section{Managerial Implications}

This study has many managerial implications as it proposes practical steps to be taken by hospitals to deal with the medical staff's perceived stress. Firstly, we can understand that anxiety and fear prevail among medical workers because of Covid-19. It is known that the pandemic has adversely affected the world economy, especially in developing countries. Health sector reforms, particularly in developing countries, are mandatory. These reforms must address the woes of the medical workers dealing with Covid-19 directly. Secondly, the services and sacrifices of medical workers must be recognized and appreciated by the government and civil society, especially the media. Hospitals' administration must ensure a supportive health climate. There is a need for introducing significant structural changes aimed at promoting an inclusive work culture within hospitals. All of this can relieve the health workers of the perceived stress caused by the current epidemic.

\section{Limitations and Future Research Directions}

Because of the exceptional circumstances, this study faced some limitations. When this study was being conducted, the medical workers were in the state of emergency and they felt overburdened because of the rising number of cases of Covid19 coming to them for treatment; this situation limited the access of the researchers to them for collecting wide range of responses via a variety of research tools. Also, the study is limited only to hospitals designated for treating Covid-19, which were in the process of development and had yet to get fully developed. Lastly, the data were collected in a limited duration of one-month (from the end of April, 2020 to the end of May, 2020). In the light of the results reached, it becomes obvious that there is room for conducting further studies in other contexts, in addition to a room for adding on other variables, such as perceived support, leadership, motivation, and skill set, etc. 


\section{Conclusion}

Stress in the workplace has greatly increased in the face of the Covid-19 epidemic, and the perceived stress has a negative impact upon both the mental and physical health of the workers, in the health care work, the effects of the perceived stress are devastating because mistake by one person can endanger the life of another person. In such situations, hospitals must adopt mechanisms to mitigate the adverse effects. Support related to the procedures, tools, and strategies used to increase the level of health safety is essential in such tense and challenging working conditions. On this basis, hospitals in the developing countries need to develop and enhance a sense of health safety in the workplace, at the level of organization as a whole, and at the levels of supervisors as well as workgroups. This would lead to making the stress level acceptable, which in turn would not affect work behavior in hospitals.

Data Availability The data of the paper, which support the analysis and results of this paper, are available with the corresponding author and the data can be obtained from the authors upon request.

\section{Compliance with Ethical Standards}

Conflict of Interest All the authors of this paper declare existence of no mutual conflict of interests.

Ethical Approval All the procedures adopted by the study, involving human participants, were in accordance with the ethical standards of the institutional and/or national research committee and with the 1964 Helsinki declaration and its later amendments or comparable ethical standards.

Informed Consent Informed consent was obtained from all individual participants of the study.

\section{References}

Abid, A., Shahzad, H., Khan, H. A., Piryani, S., Khan, A. R., \& Rabbani, F. (2020). Perceived risk and distress related to COVID-19: Comparing healthcare versus non-healthcare Workers of Pakistan. medRxiv, 8(1), 1-32.

Al-Abrrow, H. A. W. (2014). Transformational leadership and organizational performance in the public healthcare sector: The role of organizational learning and intellectual capital. Irish Journal of Management, 33(1), 27-47.

AL-Abrrow, H., Abdullah, H., \& Atshan, N. (2019a). Effect of organizational integrity and leadership behaviour on organizational excellence: Mediator role of work engagement. International Journal of Organizational Analysis, 27(4), 972-985.

AL-Abrrow, H., Alnoor, A., Ismail, E., Eneizan, B., \& Makhamreh, H. Z. (2019b). Psychological contract and organizational misbehavior: Exploring the moderating and mediating effects of organizational health and psychological contract breach in Iraqi oil tanks company. Cogent Business \& Management, 6(1), 1683123.

AL-Abrrow, H., Al-Maatoq, M., Alharbi, R, K., Alnoor, A., Abdullah, H, O., Abbas, S., \& Khattak, Z, Z. (2020). Understanding employees' responses to the COVID-19 pandemic: The attractiveness of healthcare jobs. Global Business and Organizational Excellence, 40(2), 19-33.

Al-Dubai, S. A. R., Al-Naggar, R. A., Alshagga, M. A., \& Rampal, K. G. (2011). Stress and coping strategies of students in a medical faculty in Malaysia. The Malaysian journal of medical sciences: MJMS, 18(3), 57-64.

Alnoor, A. (2020). Human capital dimensions and firm performance, mediating role of knowledge management. International Journal of Business Excellence, 20(2), 149-168.

Alnoor, A. M., Al-Abrrow, H., Abdullah, H., \& Abbas, S. (2020). The impact of self-efficacy on employees' ability to accept new technology in an Iraqi university. Global Business and Organizational Excellence, 39(2), 41-50.

Ancarani, A., Di Mauro, C., \& Giammanco, M. D. (2017). Hospital safety climate and safety behavior: A social exchange perspective. Health Care Management Review, 42(4), 341-351.

Aymen, R. A., Alhamzah, A., \& Bilal, E. (2019). A multi-level study of influence financial knowledge management small and medium enterprises. Polish Journal of Management Studies, 19(1), 21-31.

Babore, A., Lombardi, L., Viceconti, M. L., Pignataro, S., Marino, V., Crudele, M., et al. (2020). Psychological effects of the COVID-2019 pandemic: Perceived stress and coping strategies among healthcare professionals. Psychiatry Research, 293(8), 1-6.

Bjerkan, A. M. (2010). Health, environment, safety culture and climateanalysing the relationships to occupational accidents. Journal of risk research, 13(4), 445-477.

Brief, A. P., \& George, J. M. (1995). Psychological stress and the workplace: A brief comment on Lazarus outlook. Occupational stress: a handbook. Philadelphia: Taylor and Francis, 6(7), 15-20.

Bull, F. C., Al-Ansari, S. S., Biddle, S., Borodulin, K., Buman, M. P., Cardon, G., ... \& Willumsen, J. F. (2020). World Health Organization 2020 guidelines on physical activity and sedentary behaviour. British journal of sports medicine, 54(24), 1451-1462.

Cai, H., Tu, B., Ma, J., Chen, L., Fu, L., Jiang, Y., \& Zhuang, Q. (2020). Psychological impact and coping strategies of frontline medical staff in Hunan between January and march 2020 during the outbreak of coronavirus disease 2019 (COVID-19) in Hubei, China. Medical science monitor: international medical journal of experimental and clinical research, 26(4), 1-16.

Carls, G., Li, T., Panopalis, P., Wang, S., Mell, A. G., Gibson, T. B., \& Goetzel, R. Z. (2009). Direct and indirect costs to employers of patients with systemic lupus erythematosus with and without nephritis. Journal of Occupational and Environmental Medicine, 51(1), 66-79.

Chen, Q., Liang, M., Li, Y., Guo, J., Fei, D., Wang, L., et al. (2020). Mental health care for medical staff in China during the COVID-19 outbreak. The Lancet Psychiatry, 7(4), e15-e16.

Cohen, S. (1996). Psychological stress, immunity, and upper respiratory infections. Current Directions in Psychological Science, 5(3), 8689.

Cohen, S., Kamarck, T., \& Mermelstein, R. (1994). Perceived stress scale. Measuring stress: A guide for health and social scientists, $10(2), 1-2$

Danna, K., \& Griffin, R. W. (1999). Health and well-being in the workplace: A review and synthesis of the literature. Journal of Management, 25(3), 357-384.

Drapeau, A., Marchand, A., \& Beaulieu-Prévost, D. (2012). Epidemiology of psychological distress. Mental illnesses-understanding, prediction and control, 69(2), 105-106.

Fiernaningsih, N. (2020). The role of supervisory support and life balance work in increasing organizational citizenship behavior: Study at hotel employees in Malang. JPAS (Journal of Public Administration Studies), 4(2), 76-84.

Flesia, L., Monaro, M., Mazza, C., Fietta, V., Colicino, E., Segatto, B., \& Roma, P. (2020). Predicting perceived stress related to the Covid-19 
outbreak through stable psychological traits and machine learning models. Journal of Clinical Medicine, 9(10), 1-17.

Fornell, C., \& Larcker, D. F. (1981). Evaluating structural equation models with unobservable variables and measurement error. Journal of Marketing Research, 18(1), 39-50.

Franke, F., Felfe, J., \& Pundt, A. (2014). The impact of health-oriented leadership on follower health: Development and test of a new instrument measuring health-promoting leadership. German Journal of Human Resource Management, 28(1-2), 139-161.

Gavin, B., Hayden, J., Adamis, D., \& McNicholas, F. (2020). Caring for the psychological well-being of healthcare professionals in the Covid-19 pandemic crisis. Irish Medical Journal, 113(4), 51-51.

Gerbing, D. W., \& Anderson, J. C. (1988). An updated paradigm for scale development incorporating unidimensionality and its assessment. Journal of marketing research, 25(2), 186-192.

Georgiou, N., Delfabbro, P., \& Balzan, R. (2020). COVID-19-related conspiracy beliefs and their relationship with perceived stress and pre-existing conspiracy beliefs. Personality and Individual Differences, 166(7), 1-7.

Goetzel, R. Z., Anderson, D. R., Whitmer, R. W., Ozminkowski, R. J., Dunn, R. L., Wasserman, J., \& Health Enhancement Research Organization (HERO) Research Committee. (1998). The relationship between modifiable health risks and health care expenditures: An analysis of the multi-employer HERO health risk and cost database. Journal of Occupational and Environmental Medicine, 40(10), 843-854.

Grawitch, M. J., Gottschalk, M., \& Munz, D. C. (2006). The path to a healthy workplace: A critical review linking healthy workplace practices, employee well-being, and organizational improvements. Consulting Psychology Journal: Practice and Research, 58(3), 129-147.

Gray-Toft, P., \& Anderson, J. G. (1981). The nursing stress scale: Development of an instrument. Journal of Behavioral Assessment, $3(1), 11-23$.

Greenberg, N., Docherty, M., Gnanapragasam, S., \& Wessely, S. (2020). Managing mental health challenges faced by healthcare workers during covid-19 pandemic. British Medical Journal, 3(2), 368-370.

Hair, J. F., Black, W. C., Babin, B. J., \& Anderson, R. E. (2009). Multivariate data analysis (7th ed.) (pp. 1-761). Upper Saddle River, NJ: Pearson prentice hall.

Hamouche, S. (2020). COVID-19 and employees' mental health: Stressors, moderators and agenda for organizational actions. Emerald Open Research, 2(15), 1-15.

Hatcher, M. (1994). Voting and priorities in health care decision making, portrayed through a group decision support system, using analytic hierarchy process. Journal of Medical Systems, 18(5), 267-288.

Ilgen, D. R. (1990). Health issues at work: Opportunities for industrial/ organizational psychology. American Psychologist, 45(2), 273-283.

Jawed, F., Manazir, S., Zehra, A., \& Riaz, R. (2020). The novel coronavirus disease (COVID-19) pandemic: Knowledge, attitude, practice, and perceived stress among health care workers in Karachi, Pakistan. Medical Journal of the Islamic Republic of Iran (MJIRI), 34(1), 908-917.

Kagaayi, J., \& Serwadda, D. (2016). The history of the HIV/AIDS epidemic in Africa. Current HIV/AIDS Reports, 13(4), 187-193.

Kumar, M. Y., \& Bhalla, P. (2019). Stress among nursing staff in hospitals and its relation with job satisfaction, job performance and quality of nursing care: A literature review. Journal of Nurse Care, 8(3), $1-5$

Lai, J., Ma, S., Wang, Y., Cai, Z., Hu, J., Wei, N., ... \& Hu, S. (2020). Factors associated with mental health outcomes among health care workers exposed to coronavirus disease 2019. JAMA network open, 3(3), e203976-e203976.

Legido-Quigley, H., Asgari, N., Teo, Y. Y., Leung, G. M., Oshitani, H., Fukuda, K., Cook, A. R., Hsu, L. Y., Shibuya, K., \& Heymann, D.
(2020). Are high-performing health systems resilient against the COVID-19 epidemic? The Lancet, 395(10227), 848-850.

Li, L., Wan, C., Ding, R., Liu, Y., Chen, J., Wu, Z., et al. (2015). Mental distress among Liberian medical staff working at the China Ebola treatment unit: A cross sectional study. Health and Quality of Life Outcomes, 13(1), 1-6.

Lim, Y. M., Tam, C. L., \& Lee, T. H. (2013). Perceived stress, coping strategy and general health: A study on accounting students in Malaysia. Researchers World, 4(1), 88-95.

Liu, S., Lithopoulos, A., Zhang, C. Q., Garcia-Barrera, M. A., \& Rhodes, R. E. (2020a). Personality and perceived stress during COVID-19 pandemic: Testing the mediating role of perceived threat and efficacy. Personality and Individual Differences, 168(8), 1-6.

Liu, Y., Raza, J., Zhang, J., Zhu, N., \& Gul, H. (2020b). Linking autonomy support and health at work: The self-determination theory perspective. Current Psychology, 29(3), 1-13.

Makhubela, M. (2020). Assessing psychological stress in south African university students: Measurement validity of the perceived stress scale (PSS-10) in diverse populations. Current Psychology, 29(6), $1-8$.

Mearns, K., Hope, L., Ford, M. T., \& Tetrick, L. E. (2010). Investment in workforce health: Exploring the implications for workforce safety climate and commitment. Accident Analysis \& Prevention, 42(5), $1445-1454$.

Mehta, R., \& Sivadas, E. (1995). Comparing response rates and response content in mail versus electronic mail surveys. Market Research Society Journal, 37(4), 1-12.

Meo, S. A., Alhowikan, A. M., Al-Khlaiwi, T., Meo, I. M., Halepoto, D. M., Iqbal, M., \& Ahmed, N. (2020). Novel coronavirus 2019-nCoV: Prevalence, biological and clinical characteristics comparison with SARS-CoV and MERS-CoV. European Review for Medical and Pharmacological Sciences, 24(4), 2012-2019.

Mirela, B., \& Madalina-Adriana, C. (2011). Organizational stress and its impact on work performance. Annals of Faculty of Economics, 1(special), 1622-1628.

Mugrabi, F., Rozner, L., \& Peles, E. (2020). The mindfulness trait and high perceived stress changes during treatment in patients with psychiatric disorders. Current Psychology, 29(6), 1-8.

Nanjundaswamy, M. H., Pathak, H., \& Chaturvedi, S. K. (2020). Perceived stress and anxiety during COVID-19 among psychiatry trainees. Asian Journal of Psychiatry, 54(2), 1-8.

News-Urdu, E. (2020). Corona virus in Pakistan. Corona after lockdown. Lahore, Punjab: Express News.

Podder, I., Agarwal, K., \& Datta, S. (2020). Comparative analysis of perceived stress in dermatologists and other physicians during home-quarantine and COVID-19 pandemic with exploration of possible risk factors-A web-based cross-sectional study from eastern India. Dermatologic Therapy, 33(4), 54-64.

Prasad, K. D. V., Vaidya, R., \& Anil Kumar, V. (2018). Association among occupational stress factors and performance at workplace among agricultural research sector employees at Hyderabad, India. Pacific Business Review International (TSI), 10(7), 27-36.

Qiu, Y., Chen, X., \& Shi, W. (2020). Impacts of social and economic factors on the transmission of coronavirus disease 2019 (COVID19) in China. Journal of Population Economics, 33(4), 1127-1172.

Quick, J. D., Horn, R. S., \& Quick, J. C. (1987). Health consequences of stress. Journal of Organizational Behavior Management, 8(2), 19 36.

Qureshi, M. M., Khan, T. A., Mohsin, S., Zahid, M. A., Ashraf, M., \& Channa, A. A. (2020). The price of battling COVID-19: A crosssectional survey. Pakistan Armed Forces Medical Journal, 70(2), $68-74$.

Rana, W., Mukhtar, S., \& Mukhtar, S. (2020). Mental health of medical workers in Pakistan during the pandemic COVID-19 outbreak. Asian Journal of Psychiatry, 5(51), 1-2. 
Remuzzi, A., \& Remuzzi, G. (2020). COVID-19 and Italy: what next?. The Lancet, 395(10231), 1225-1228.

Schneider, S., \& Becker, S. (2005). Prevalence of physical activity among the working population and correlation with work-related factors: Results from the first German National Health Survey. Journal of Occupational Health, 47(5), 414-423.

Shadmi, E., Chen, Y., Dourado, I., Faran-Perach, I., Furler, J., Hangoma, P., et al. (2020). Health equity and COVID-19: Global perspectives. International Journal for Equity in Health, 19(1), 1-16.

Shahsavarani, A. M., Azad Marz Abadi, E., \& Hakimi Kalkhoran, M. (2015). Stress: Facts and theories through literature review. International Journal of Medical Reviews, 2(2), 230-241.

Shanafelt, T., Ripp, J., \& Trockel, M. (2020). Understanding and addressing sources of anxiety among health care professionals during the COVID-19 pandemic. Jama, 323(21), 2133-2134.

Sheehan, M. C., \& Fox, M. A. (2020). Early warnings: The lessons of COVID-19 for public health climate preparedness. International Journal of Health Services, 50(3), 264-270.

Sim, M. (2020). The COVID-19 pandemic: Major risks to healthcare and other workers on the front line. Occupational and Environmental Medicine, 77(5), 281-282.

Sohrabi, C., Alsafi, Z., O'Neil, N., Khan, M., Kerwan, A., Al-Jabir, A., \& Agha, R. (2020). World Health Organization declares global emergency: A review of the 2019 novel coronavirus (COVID-19). International Journal of Surgery, 76(4), 71-76.

Sonnentag, S. (2015). Dynamics of wellbeing. Annual Review of Organization Psychology and organizational Behavior, 2(4), 261293.

Sonnentag, S., \& Frese, M. (2003). Stress in organizations. Handbook of psychology, 453-491.

Stokols, D. (1992). Establishing and maintaining healthy environments: Toward a social ecology of health promotion. American Psychologist, 47(1), 6-22.

Styra, R., Hawryluck, L., Robinson, S., Kasapinovic, S., Fones, C., \& Gold, W. L. (2008). Impact on health care workers employed in high-risk areas during the Toronto SARS outbreak. Journal of Psychosomatic Research, 64(2), 177-183.

Urooj, U., Ansari, A., Siraj, A., Khan, S., \& Tariq, H. (2020). Expectations, fears and perceptions of doctors during Covid-19 pandemic. Pakistan Journal of Medical Sciences, 36(COVID), 19-54.

Usman, N., Mamun, M. A., \& Ullah, I. (2020). COVID-19 infection risk in pakistani health-care workers: The cost-effective safety measures for developing countries. Social Health and Behavior, 3(3), 75-77.

Velavan, T. P., \& Meyer, C. G. (2020). The COVID-19 epidemic. Tropical Medicine \& International Health, 25(3), 278-280.

Volpato, S., Landi, F., \& Incalzi, R. A. (2020). A frail health care system for an old population: Lesson form the COVID-19 outbreak in Italy. The Journals of Gerontology: Series A, 75(9), 126-127.

Wang, W., Tang, J., \& Wei, F. (2020). Updated understanding of the outbreak of 2019 novel coronavirus (2019-nCoV) in Wuhan, China. Journal of Medical Virology, 92(4), 441-447.

Watson, M. F., Bacigalupe, G., Daneshpour, M., Han, W. J., \& ParraCardona, R. (2020). COVID-19 interconnectedness: Health inequity, the climate crisis, and collective trauma. Family Process, 59(3), 832-846.

Xiang, Y. T., Zhao, Y. J., Liu, Z. H., Li, X. H., Zhao, N., Cheung, T., \& Ng, C. H. (2020). The COVID-19 outbreak and psychiatric hospitals in China: Managing challenges through mental health service reform. International Journal of Biological Sciences, 16(10), 17411744.

Zandi, G., Shahzad, I., Farrukh, M., \& Kot, S. (2020). Supporting role of society and firms to COVID-19 management among medical practitioners. International Journal of Environmental Research and Public Health, 17(21), 1-16.

Zweber, Z. M., Henning, R. A., \& Magley, V. J. (2016). A practical scale for multi-faceted organizational health climate assessment. Journal of Occupational Health Psychology, 21(2), 250-259.

Publisher's note Springer Nature remains neutral with regard to jurisdictional claims in published maps and institutional affiliations. 